\title{
Assessment of inflammation in the rheumatoid knee joint: correlation between clinical, radioisotopic, and thermographic methods
}

\author{
M DE SILVA, ${ }^{*}$ V KYLE, ${ }^{1}$ B HAZLEMAN, ${ }^{1}$ R SALISBURY, ${ }^{1} \dagger$ \\ P PAGE THOMAS, ${ }^{1}$ AND P WRAIGHT ${ }^{2}$
}

From the Departments of ${ }^{1}$ Rheumatology and ${ }^{2}$ Nuclear Medicine, Addenbrooke's Hospital, Hills Road, Cambridge

SUMMARY Standard clinical methods of assessing joint inflammation are being supplemented increasingly by radioisotopic and thermographic studies. However, the correlation between these different methods has not been firmly established. In the quantification of synovitis by infrared thermography we have shown that the heat distribution index (HDI) based on thermal pattern is more reliable and is less affected by diurnal variations in joint temperature than the commonly used thermographic index, which is based on average skin temperature values. In 20 patients with rheumatoid arthritis whose knees were being treated with intra-articular steroid we obtained 184 serial paired observations over a period of 24 weeks for clinical assessment, HDI, and ${ }^{99 m} \mathrm{Tc}$ pertechnetate uptake. We found significant correlations $(p<0.001)$ between the three methods of assessment (except for pain and HDI $(p=0 \cdot 116)$ ).

Key words: rheumatoid arthritis, treatment, disease activity.

There is a need for objective, reproducible, relevant, and accurate methods of assessing inflammatory joint disease. Many parameters are based on patients' symptoms, which may not give an accurate indication of the progress of the disease, ${ }^{1}$ and laboratory evaluation may be unhelpful. The number of indices of disease activity available testify to the absence of any single acceptable parameter. This is partly because of the complex nature of rheumatoid disease but also reflects the subjective nature of most of the indices. Absolute identification and quantification of inflamed tissue would require invasive methods, which are both impracticable and unjustifiable. However, safe, sensitive, objective, reproducible, and quantifiable methods of assessment are desirable. Radioisotopic and thermographic methods have been developed to provide such methods and complement the information

Accepted for publication 11 September 1985.

Correspondence to Dr B Hazleman, Rheumatology Research Unit. Unit E6, Addenbrooke's Hospital, Hills Road. Cambridge CB2 2QQ.

Current addresses: *Department of Rheumatology, Prince Charles Hospital, Merthyr Tydfil, Wales. +Department of Rheumatology, Manchester Royal Infirmary, Manchester. obtained by clinical methods. Of the several different radioisotopic techniques that have been used, ${ }^{99 \mathrm{~m}} \mathrm{Tc}$ pertechnetate uptake ( $\mathrm{Tc}$ ) as described by Dick et al. ${ }^{2}$ has been used most frequently.

Thermographic equipment produces a multiple isotherm scan of a joint area, which is conveniently displayed on a colour monitor. This thermal image is usually quantified by an integrated numerical expression of the isothermal image to produce a thermographic index (TI) ${ }^{3}$

Recently, Salisbury et al. introduced a heat distribution index (HDI) ${ }^{4}$ and showed that this correlated better with clinical assessment than the thermographic index (TI). Therefore we chose to use the HDI, which was developed in this unit for our present study. Correlations between clinical assessment and ${ }^{99 \mathrm{~m}} \mathrm{Tc}$ pertechnetate uptake (Tc), ${ }^{56}$ between clinical assessment and $\mathrm{TI}^{3}{ }^{3}$ and between clinical assessment and $\mathrm{HDI}^{4}$ have already been demonstrated. However, the relationship between radioisotopic methods and thermography has not been established. ${ }^{8}$ The aim of this study was to examine the inter-relationship between clinical assessment, Tc, and HDI in rheumatoid patients with active synovitis of one or both knee joints. 


\section{Patients and methods}

Twenty outpatients with classical or definite RA (American Rheumatism Association criteria) were included whose disease activity was well controlled except for active synovitis in one or both knees. Their details are given in Table 1. Patients were assessed at the start of the study and at four weekly intervals thereafter according to a standard protocol. Each group of assessments was carried out at roughly the same time before 12 noon. Intraarticular injections were given at the start of the study and repeated if necessary by the same clinician using standard procedures (this will be the subject of a separate report).

\section{CLINICAL ASSESSMENT}

This consisted of the following: pain, swelling, and tenderness graded by the physician on a scale of $0-3$ $(0=$ none, $1=$ mild, $2=$ moderate, $3=$ severe $)$. Morning stiffness in minutes was graded $0-3$ (up to 15 minutes $=0,>15$ minutes but $<30=1,>30$ minutes but $<60=2,>60$ minutes $=3$ ). The sum of the numerical values for each of these parameters was used as a joint score with a range from 0 to 12).

Patients were requested to note down the time of onset of relief of symptoms, with particular reference to pain, swelling, and stiffness and the date on which they considered each of these parameters had reverted to the preinjection state.

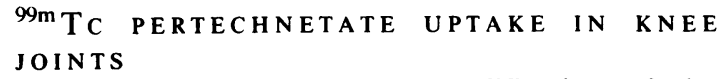
method described by Dick et al. ${ }^{2} 100 \mu \mathrm{Ci}(4 \mathrm{MBq})$ of ${ }^{99 \mathrm{~m}} \mathrm{Tc}$ pertechnetate was injected intravenously, and the ${ }^{99 \mathrm{~m}} \mathrm{Tc}$ activity in the knees was measured at 15 and 20 minutes. The patient was positioned with a 2 inch scintillation counter over each knee, the end of the collimator being in line with the patellar surface. The activity measured within the field of view of each counter was expressed as a percentage of the injected dose by reference to a phantom counter with similar geometry. A correction was applied for the expected normal uptake in a patient of that height and weight. Subjects receiving pertechnetate

Table 1 Patient details

\begin{tabular}{ll}
\hline Male/female & $7 / 13$ \\
Age in years & Mean $55 \cdot 6$ \\
& Range 26-76 \\
Disease duration in & Mean 7-6 \\
years & Range 2-20 \\
\hline
\end{tabular}

for thyroid scans were used to establish the norma $\frac{\text { on }}{\text {. }}$ range.

T H E R M O G R A P H Y

Thermography was carried out in a draught free을 room with ambient temperature controlled to $\frac{\bar{s}}{7}$ $20 \cdot 5 \pm 5^{\circ} \mathrm{C}$ and humidity $50 \pm 10 \%$. Subjects were $\underset{\mathbb{Q}}{\mathbb{2}}$ seated in a modified dentist's chair with their limbso exposed and a sleeveless jacket worn.

An AGA thermovision 680 medical system was used to detect infrared emission, and all thermo- $\vec{\omega}$ grams were recorded in digital form on magnetic tape for subsequent analysis by a Varian $620_{0}^{2}$ computer. The camera was placed parallel (vertical and horizontal planes) and at a distance of $1.2 \mathrm{~m}$ from knee joints. Knees were flexed at $90^{\circ} \mathrm{C}$. Thermograms were recorded of the lateral aspect of the joint. In all instances recordings were made after a 15 minute equilibration period in the room. The HDI, which reflects the pattern and spread of temperature over a joint, was then calculated aspreviously described by Salisbury et al. ${ }^{4}$ A region of interest on the thermogram is chosen to corresponcs to a fixed area over the joint. The analogue therma $\zeta$ signal from the AGA $680 \mathrm{M}$ signal is digitised intoo 256 grey levels by an $A / D$ converter. A count is then made of the number of picture elements (pixels) which occur at each grey level. Finally, each numben is divided by the total number of picture points in? the area of interest giving a relative frequencyo distribution (RFD). A calculation of the width of the RFD is made as \pm 1 SD from the mean frequency $=$ heat distribution index. The HDI is. thus an approximation to the width of the majof components of RFD curves and has been found to be a useful thermal parameter in arthritic patients 3

S T A T IS T I C S

Spearman correlation coefficients were used throughout the study.

\section{Results}

For the group of 20 patients a total of 184 values were obtained for each of the variables. The groupe mean values and standard deviations for the assess ment parameters are given in Table 2.

HEAT DISTRIBUTION INDEX VERSUS ${ }^{99 m}$ T C PERTECHNETATE UPTAKE

The values for both parameters were symmetricall $\$$ distributed as indicated by the mean and mediaw values (Table 2). A correlation coefficient of $0 \cdot 39 \bar{z}$ with $\mathrm{p}=<0.001$ was obtained. 
Table 2 Results of assessment parameters

\begin{tabular}{|c|c|c|c|c|c|c|}
\hline Variables & $N o$ & Mean & $S D$ & Median & Min & $\operatorname{Max}$ \\
\hline${ }^{{ }^{4 m} \mathrm{~m}} \mathrm{Tc}$ & 184 & $0 \cdot 681$ & $0 \cdot 382$ & 0.649 & 0.036 & $1 \cdot 260$ \\
\hline HDI & 184 & $1 \cdot 254$ & $0 \cdot 361$ & $1 \cdot 234$ & 0.460 & $2 \cdot 020$ \\
\hline Pain & 184 & $1 \cdot 130$ & 1.073 & 1.000 & 0 & 3.000 \\
\hline Swelling & 184 & 1.097 & $1 \cdot() 40$ & 1.000 & 0 & $3 \cdot 000$ \\
\hline Stiffness & 184 & $1 \cdot 005$ & $1 \cdot 005$ & $1 \cdot 000$ & 0 & $3 \cdot 000$ \\
\hline Tenderness & 184 & $1 \cdot 831$ & 0.957 & 1.000 & 0 & $3 \cdot 000$ \\
\hline Joint score & 184 & $4 \cdot 065$ & 2.994 & $4 \cdot 00$ & 0 & $12 \cdot 000$ \\
\hline
\end{tabular}

$\mathrm{SD}=$ standard deviation.

Table 3 Correlation between technetium and clinical assessment

\begin{tabular}{lll}
\hline Variables & $\begin{array}{l}\text { Correlation } \\
\text { coefficients }\end{array}$ & $p$ Value \\
\hline Pain & $0 \cdot 418$ & $0 \cdot 0001$ \\
Swelling & 0.479 & $0 \cdot 0001$ \\
Stiffness & $0 \cdot 414$ & $0 \cdot 0001$ \\
Tenderness & $0 \cdot 327$ & $0 \cdot 0001$ \\
Joint score & 0.577 & $0 \cdot 0001$ \\
\hline
\end{tabular}

Table 4 Correlation between HDI and clinical assessment (CA)

\begin{tabular}{lll}
\hline Variables & $\begin{array}{l}\text { HDI/CA } \\
\text { correlation } \\
\text { coefficients }\end{array}$ & $p$ Value \\
\hline Pain & $0 \cdot 116$ & $0 \cdot 116 \mathrm{NS}$ \\
Swelling & $0 \cdot 439$ & $0 \cdot 0001$ \\
Stiffness & $0 \cdot 179$ & $0 \cdot 015$ \\
Tenderness & $0 \cdot 224$ & $0 \cdot 002$ \\
Joint score & $0 \cdot 326$ & $0 \cdot 0001$ \\
\hline
\end{tabular}

CLINICAL ASSESSMENT VERSUS ${ }^{99 \mathrm{~m}}$ TC PERTECHNETATE UPTAKE

The correlation coefficients and $p$ values which were obtained are shown in Table 3 .

\section{CLINICAL ASSESSMENT VERSUS HEAT}

\section{DISTRIBUTION INDEX}

Table 4 gives values of HDI and clinical assessment parameters. All were significantly correlated with HDI except for pain $(p=0 \cdot 116)$.

\section{Discussion}

Assessing rheumatoid knees, we have shown a significant correlation between pertechnetate uptake and the heat distribution index, which has not previously been demonstrated. We also confirmed a correlation between pertechnetate uptake and clinical assessment, and between the heat distribution index and all components of clinical assessment except pain.

Although Dick and Grennan, ${ }^{6}$ Haataja et al., ${ }^{9}$ and Paterson et al. ${ }^{8}$ all found a correlation between pertechnetate uptake and clinical assessment, Huskisson's group did not. ${ }^{10}$ His study was significantly different from ours in that a small number of patients (six) were assessed using several joints and three treatment options were used-placebo, an oral non-steroidal anti-inflammatory agent, or a 'drug of unknown activity'. It is easier for patients to assess a single active joint rather than several, and it has also been shown by Dick ${ }^{11}$ that the relief of symptoms and reduction in radioisotope uptake are greater when a rheumatoid joint is treated with intra-articular steroid rather than oral agents or placebo. Another factor which may have contributed to the failure to show a correlation between pertechnetate uptake and clinical assessment in Huskisson's study was the different method used to calculate ${ }^{99 \mathrm{~m}}$ Tc clearance.

The radioisotope technique used by Paterson et al. ${ }^{8}$ also differed from ours but gave equivalent results. They scanned the whole length of the body with collimated counters. The average counts were taken to be proportional to the total administered activity, and the peak counts for each knee were expressed in relation to this.

Reports of the relationship between thermographic index and clinical assessment have also been variable. Bacon et al. ${ }^{3}$ found a good correlation between the two, but Huskisson ${ }^{70}$ and Paterson ${ }^{8}$ found the thermographic index of limited value because of the changes in ambient temperature, the timing of measurements in individual patients, and the need to measure intraknee temperature differences to obtain meaningful results. However, calculation of the heat distribution index overcomes many of these shortcomings. It reflects the pattern and spread of heat over a joint and correlates well with the clinical assessment of the severity of the 
inflammation. The thermographic index, which reflects mean surface temperature, is less sensitive in demonstrating differences.

This study has shown a correlation between two objective methods of assessment and has confirmed correlations with clinical assessment. The correlation coefficients between Tc uptake and clinical assessment are generally better than those between HDI and clinical assessment, but thermographic assessment has the advantage of being easier to perform and no radioisotope is involved.

We thank the Arthritis and Rheumatism Council for support and Dr R Hanka, Statistics Group. Department of Community Medicine for statistical advice.

\section{References}

1 Beecher H K. Measurement of subjective responses. Oxford: Oxford University Press. 1959.

2 Dick W C. Neufeld R R. Prentice A G. et al. Measurement of joint inflammation. Ann Rheum Dis 1970; 29: 135-7.

3 Bacon P. Collins A J. Ring F J. Cosh J. Thermography in the assessment of inflammatory arthritis. Clin Rheum Dis 1976: 2 응. 51-65.

4 Salisbury R S. Parr G. De Silva M. Hazleman B L. Pag Thomas D P. Heat distribution over normal and abnorma joints: Thermal pattern and quantification. Ann Rheum Di 1983: 42: 494-9.

5 Oka M. Rekonen A. Ruotsi A. Kuikka J. Measurement of systemic inflammatory activity in rheumatoid arthritis by th $\vec{D}$ ${ }^{\text {M }}{ }^{\mathrm{m}} \mathrm{Tc}$ method. Scand J Rheumatol 1973: 2: 101-7.

6 Dick W C. Grennan D M. Radioisotopes in the study of normates and inflamed joints. Clin Rheum Dis 1976: 2: 67-75.

7 Ring E F J. Collins A J. Bacon P A. Cosh J A. Quantitation of thermography in arthritis using multi-isothermal analysis. II Effect of nonsteroidal anti-inflammatory therapy on the ther $\vec{\omega}$ mographic index. Ann Rheum Dis 1974: 33: 353-6.

8 Paterson J. Watson W S. Tensdale E. et al. Assessment of rheumatoid inflammation in the knee joint. Ann Rheum Dis 1978: 37: 48-52

9 Haataja M. Evaluation of the activity of rheumatoid arthritis Scand J Rheumatol 1975: 4 (suppl): 1-54.

10 Huskisson E C. Berry H. Browett J P. Balme $H$ W V Measurements of inflammation. II Comparison of technctiun? clearance and thermography with standard methods in a clinical trial. Ann Rheum Dis 1973: 32: 99-102.

11 Dick W C. The use of radioisotopes in normal and disease $\frac{f}{6}$ joints. Semin Arthritis Rheum 1972: 4: 301-17. 